\title{
Commentary on Clinical Predictors and Prognostic Model for Pediatric Lymphoblastic Lymphoma Treated with Uniform BFM90 Protocol: A Single-Center Experience of 65 Patients from Asia
}

There are insufficient data on the outcomes and their clinical predictors in pediatric patients with lymphoblastic lymphomas (LBLs). Molecular genetics of pediatric LBLs and acute lymphoblastic leukemia (ALL) overlap to some extent. Risk stratification-directed treatment is the standard of care in the treatment of ALL, and such a risk stratification model has not been developed for the clinical use in LBL patients. To bridge this gap, a retrospective analysis of 65 consecutive patients with pediatric LBL over 15 years, treated with BFM90 protocol, was carried out and the outcomes were assessed in terms of overall survival (OS) and event-free survival (EFS) ${ }^{[1]}$

At the end of induction, $57 \%$ of patients had a complete remission, $28 \%$ had a partial remission, $6 \%$ had a progressive disease, and $3 \%$ had a stable disease. Treatment-related mortality occurred in three patients overall and 20 patients relapsed. After a median follow-up of 54.57 months, 10 -year EFS was $62 \%$ and OS was $71 \%$. These outcomes were $15 \%-20 \%$ lower than those reported from developed countries. ${ }^{[2,3]}$

On multivariate analysis, three predictors of poor OS and EFS were identified - symptom duration $<30$ days, white blood cell count $>12,000 /$ cumm, and serum albumin $<3.5 \mathrm{~g} / \mathrm{dl}$. A prognostic model was devised which showed that OS was $92 \%$ if no risk factors were present versus $37 \%$ if two or three risk factors were present. Twenty percent of patients had two or three risk factors and had poor outcomes both as a result of increased toxicity, higher relapses, and higher deaths ( 3 out of 14 in the presence of risk factors vs. none in the other group).

Age, sex, presence of mediastinal mass, bulky disease, stage of disease, and elevated serum lactate dehydrogenase were earlier investigated as prognostic markers with variable results. However, the study population and the results were heterogeneous. As majority of patients (90\%) of LBL have Stage III/IV disease, stratification of patients into localized and disseminated disease based on stage is not a useful measure in making treatment decisions.

Among novel prognostic markers, molecular profile, minimal residual disease (MRD), minimal disseminated disease (MDD), and use of positron emission tomography (PET) scan were studied in LBLs. Among the molecular markers, the presence of NOTCH1 and FBXW7 mutations was associated with favorable prognosis, while loss of heterozygosity at $6 \mathrm{q}$ and PTEN mutations were associated with adverse prognosis. Based on these markers, a prognostic genetic classifier for risk group stratification for T-cell LBL has been proposed. ${ }^{[4]}$ MRD was studied as a significant risk factor for relapse. Patients with detectable disease in bone marrow, i.e., MDD by flow cytometry $(0.01 \%)$, had varying prognosis corresponding to the levels of MDD present. ${ }^{[5]}$ Postinduction PET-computed tomography (CT) has been shown to improve the ability to detect residual disease, thereby affecting the treatment decisions. $^{[6]}$

To conclude, the current study identified useful clinical predictors, which are readily available, inexpensive, and easy to use, that can help predict the outcomes of the patients. This study identifies the need for tailored therapy as per the prognostic score which can help reduce treatment-related mortality and relapses. In future, comprehensive, multicentric, prospective trial incorporating both clinical predictors and novel markers such as molecular profile, MRD, MDD, and use of PET-CT is required to further investigate on a risk-oriented approach in LBL.

\section{Sindhu Chitikela, Deepam Pushpam}

Department of Medical Oncology, AIIMS, New Delhi, India

Address for correspondence: Dr. Deepam Pushpam, The Medical Oncology Centre, Dr. B.R.A. IRCH, AIIMS, New Delhi - 110 029, India. E-mail: deepampushpam@gmail.com

Submitted: 13-Jan-2020

Revised: 22-Jan-2020

Accepted: 28-Feb-2020

Published: 24-Apr-2020

\section{References}

1. Patel A, Tiwari A, Biswas B, Chand Sharma M, Vishnubhatla S, Bakhshi S. Clinical predictors and prognostic model for pediatric lymphoblastic lymphoma treated with uniform BFM90 protocol: A single-center experience of 65 patients from Asia. Clin Lymphoma Myeloma Leuk 2019;19:e291-8.

2. Termuhlen AM, Smith LM, Perkins SL, Lones M, Finlay JL, Weinstein $\mathrm{H}$, et al. Disseminated lymphoblastic lymphoma in children and adolescents: Results of the COG A5971 trial: A report from the Children's Oncology Group. Br J Haematol 2013;162:792-801.

3. Reiter A, Schrappe M, Ludwig WD, Tiemann M, Parwaresch R, Zimmermann M, et al. Intensive ALL-type therapy without local radiotherapy provides a $90 \%$ event-free survival for children with T-cell lymphoblastic lymphoma: A BFM group report. Blood 2000;95:416-21.

4. Balbach ST, Makarova O, Bonn BR, Zimmermann M, Rohde M, Oschlies I, et al. Proposal of a genetic classifier for risk group stratification in pediatric T-cell lymphoblastic lymphoma reveals differences from adult T-cell lymphoblastic leukemia. Leukemia 2016;30:970-3. 
5. Coustan-Smith E, Sandlund JT, Perkins SL, Chen H, Chang M, Abromowitch $\mathrm{M}$, et al. Minimal disseminated disease in childhood T-cell lymphoblastic lymphoma: A report from the Children's Oncology Group. J Clin Oncol 2009;27:3533-9.

6. Cortelazzo S, Ferreri A, Hoelzer D, Ponzoni M. Lymphoblastic lymphoma. Crit Rev Oncol Hematol 2017;113:304-17.
This is an open access journal, and articles are distributed under the terms of the Creative Commons Attribution-NonCommercial-ShareAlike 4.0 License, which allows others to remix, tweak, and build upon the work non-commercially, as long as appropriate credit is given and the new creations are licensed under the identical terms.

\begin{tabular}{|l|l|}
\hline \multicolumn{2}{|c|}{ Access this article online } \\
\hline Quick Response Code: & Website: \\
& www.ijmpo.org \\
\cline { 2 - 2 } & DOI: \\
\hline
\end{tabular}

How to cite this article: Chitikela S, Pushpam D. Commentary on clinical predictors and prognostic model for pediatric lymphoblastic lymphoma treated with uniform BFM90 protocol: A single-center experience of 65 patients from Asia. Indian J Med Paediatr Oncol 2020;41:67-8. 